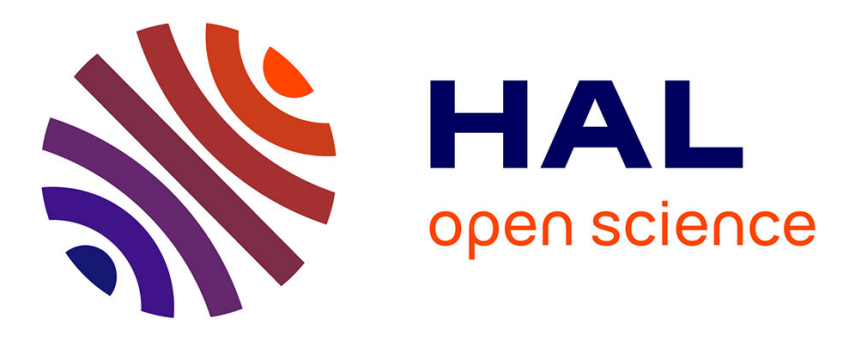

\title{
Mixing antiferromagnets to tune NiFe-[IrMn/FeMn] interfacial spin-glasses, grains thermal stability, and related exchange bias properties
}

K. Akmaldinov, C. Ducruet, C. Portemont, I. Joumard, I. L. Prejbeanu, B. Dieny, Vincent Baltz

\section{To cite this version:}

K. Akmaldinov, C. Ducruet, C. Portemont, I. Joumard, I. L. Prejbeanu, et al.. Mixing antiferromagnets to tune $\mathrm{NiFe}-[\mathrm{IrMn} / \mathrm{FeMn}]$ interfacial spin-glasses, grains thermal stability, and related exchange bias properties. Journal of Applied Physics, 2014, 115, pp.17B718. 10.1063/1.4864144 . hal-01683648

\section{HAL Id: hal-01683648 https://hal.science/hal-01683648}

Submitted on 19 May 2019

HAL is a multi-disciplinary open access archive for the deposit and dissemination of scientific research documents, whether they are published or not. The documents may come from teaching and research institutions in France or abroad, or from public or private research centers.
L'archive ouverte pluridisciplinaire HAL, est destinée au dépôt et à la diffusion de documents scientifiques de niveau recherche, publiés ou non, émanant des établissements d'enseignement et de recherche français ou étrangers, des laboratoires publics ou privés. 


\title{
Mixing antiferromagnets to tune NiFe-[IrMn/FeMn] interfacial spin-glasses, grains thermal stability, and related exchange bias properties
}

\author{
K. Akmaldinov, ${ }^{1,2}$ C. Ducruet,${ }^{2}$ C. Portemont, ${ }^{2}$ I. Joumard, ${ }^{1}$ I. L. Prejbeanu, ${ }^{1}$ B. Dieny, ${ }^{1}$ \\ and V. Baltz $z^{1, a)}$ \\ ${ }^{1}$ SPINTEC, UMR 8191 CNRS/INAC-CEA/UJF-Grenoble 1/Grenoble-INP, F-38054 Cedex, France \\ ${ }^{2}$ CROCUS Technology, F-38025 Grenoble, France
}

(Presented 6 November 2013; received 19 September 2013; accepted 4 November 2013; published online 6 February 2014)

\begin{abstract}
Spintronics devices and in particular thermally assisted magnetic random access memories require a wide range of ferromagnetic/antiferromagnetic (F/AF) exchange bias (EB) properties and subsequently of AF materials to fulfil diverse functionality requirements for the reference and storage. For the reference layer, large EB energies and high blocking temperature $\left(T_{B}\right)$ are required. In contrast, for the storage layer, mostly moderate $T_{B}$ are needed. One of the present issues is to find a storage layer with properties intermediate between those of IrMn and FeMn and in particular: (i) with a $\mathrm{T}_{\mathrm{B}}$ larger than FeMn for better stability at rest-T but lower than IrMn to reduce power consumption at write- $\mathrm{T}$ and (ii) with improved magnetic interfacial quality, i.e., with reduced interfacial glassy character for lower properties dispersions. To address this issue, the EB properties of F/AF based stacks were studied for various mixed [ $\mathrm{IrMn} / \mathrm{FeMn}$ ] AFs. In addition to EB loop shifts, the F/AF magnetic interfacial qualities and the AF grains thermal stability are probed via measurements of the low- and high-temperature contributions to the $T_{B}$ distributions, respectively. A tuning of the above three parameters is observed when evolving from IrMn to FeMn via [IrMn/FeMn] repetitions. C 2014 AIP Publishing LLC. [http://dx.doi.org/10.1063/1.4864144]
\end{abstract}

Spintronics thermally assisted magnetic random access memories (TA-MRAM) applications ${ }^{1}$ use two ferromagnetic/ antiferromagnetic (F/AF) exchange bias (EB) bilayers: ${ }^{2}$ one for reference and one for storage. The blocking temperature $\left(T_{B}\right)$ is the temperature $(T)$ above which the $F$ is no longer pinned by the AF. It depends on various parameters among which the F/AF interfacial coupling, the AF bulk properties and time. ${ }^{2}$ In particular, $\mathrm{T}_{\mathrm{B}}$ increases with the $\mathrm{F}$ magnetization sweep-rate. ${ }^{3,4}$ At rest- $\mathrm{T}$, both the reference and storage layers magnetization must withstand thermal activation, i.e., $\mathrm{T}_{\mathrm{B}}$ must be much larger than the rest-T. During writing, the TA-MRAM cell is simultaneously heated for a few nanoseconds at a $\mathrm{T}$ of about $200{ }^{\circ} \mathrm{C}$ thanks to a current flowing through the tunnel barrier and subjected to a magnetic field pulse of tens of Oersteds. The reference layer with a high $T_{B}$ (e.g., pinned to $\mathrm{PtMn}^{2}$ ) remains unaffected by this. In contrast, the storage layer with a moderate $\mathrm{T}_{\mathrm{B}}$ (e.g., pinned to IrMn or $\mathrm{FeMn}^{2}$ ) unpins at the write- $\mathrm{T}$ so that its magnetization switches in the applied field direction. ${ }^{1}$ Engineering the storage layer thus requires compromises since its critical-T needs to be adjusted above the rest-T but below the write-T. TA-MRAM are mostly based on PtMn for the reference layer and IrMn or FeMn for the storage one. ${ }^{1,5}$ One of the present industrial issues with regards to TA-MRAM is to find a storage layer with intermediate properties between those of IrMn and FeMn and in particular with a critical-T larger than FeMn for better stability at rest-T but lower than IrMn to reduce power consumption at write-T. Another issue concerns the magnetic interfacial quality, i.e., the amount of

\footnotetext{
${ }^{\text {a)} E l e c t r o n i c ~ m a i l: ~ v i n c e n t . b a l t z @ c e a . f r . ~}$
}

interfacial spin-glasses that need to be as small as possible since it is believed to mainly contribute to cell to cell dispersions after patterning the sheet film. ${ }^{17}$ Additives like $\mathrm{Cr}$ enhance AFs corrosion and stress resistance. To some extent, they also tune the AF Néel-T, the F/AF $T_{B}$, and the loop shift amplitude $\left(\mathrm{H}_{\mathrm{E}}\right)^{6-8}$ To this adds $\mathrm{AF}$ laminations ${ }^{9}$ and stoichiometry adjustments in the range where the compounds remain AF. ${ }^{10-13}$ Varying the layers thicknesses is another way to enlarge the range of $\mathrm{EB}$ properties since, for example, $\mathrm{H}_{\mathrm{E}}$ is inversely proportional to the $\mathrm{F}$ thickness and $\mathrm{T}_{\mathrm{B}}$ depends on the AF thickness. ${ }^{2}$ Yet, most of these adjustments either do not influence the F/AF interface or neglect their impact on the amount of interfacial spin-glass like phases. ${ }^{14-19}$ For example, although varying the AF (e.g., IrMn) thickness reduces $T_{B}$, it makes no difference on the amount of interfacial spin-glasses. Via the combination of a specific procedure commonly carried out for measurements of $\mathrm{T}_{\mathrm{B}}$ distributions $\left(\mathrm{DT}_{\mathrm{B}}\right)$ above room- $\mathrm{T}^{20}$ and the alternative use of a sufficiently low reference- $\mathrm{T}^{17}$ (usually $4 \mathrm{~K}$ ), we recently quantified the magnetic interfacial quality of $\mathrm{F} / \mathrm{AF}$ bilayers (i.e., the interfacial glassy character). ${ }^{17-19}$ The method is fairly easy to implement in laboratories and provides data usually obtained via large scale facilities experiments. For example, x-ray magnetic circular dichroism results obtained from synchrotron radiation experiments give the amount of frozen AF spins, at room-T usually, ${ }^{21}$ when our laboratory method provides the complement, i.e., the amount of unfrozen spins at and above room-T. ${ }^{17-19}$

The present study focuses on finding an appropriate AF material for EB of the storage layer in TA-MRAM with intermediate properties between those of IrMn and FeMn. It mixes 
usual $\mathrm{IrMn}$ and FeMn in the form of [ $\mathrm{IrMn} / \mathrm{FeMn}]$ repetitions in an attempt to widen the coverage of available AFs and F/AF properties; interface quality included ${ }^{14-19}$ for the storage layer. Therefore, in addition to EB loop shifts, the F/AF magnetic interfacial qualities ${ }^{14-19}$ and the AF grains thermal stability ${ }^{22-24}$ are studied via measurements of the low- ${ }^{17}$ and high-temperature ${ }^{22}$ contributions to $\mathrm{DT}_{\mathrm{B}}$, respectively.

For this work, buffer/CoFeB $(1.2 \mathrm{~nm}) / \mathrm{Mg}(1.4 \mathrm{~nm}$, naturally oxidized)/F/AF/Ta $(5 \mathrm{~nm})$, with $\mathrm{F}=\mathrm{CoFeB}(2 \mathrm{~nm}) / \mathrm{NiFe}$ $(1.5 \mathrm{~nm}) \quad$ and $\mathrm{AF}=\mathrm{IrMn} \quad(10 \mathrm{~nm}), \quad[\mathrm{IrMn} \quad(\mathrm{tnm}) / \mathrm{FeMn}$ $(\mathrm{t} \mathrm{nm})]_{\mathrm{xN}},[\mathrm{FeMn}(\mathrm{t} \mathrm{nm}) / \mathrm{IrMn}(\mathrm{t} \mathrm{nm})]_{\mathrm{xN}}$ and FeMn $(10 \mathrm{~nm})$, are deposited onto silicon substrates by sputtering. ${ }^{3}$ The IrMn and FeMn thicknesses $t$ and the number of repetitions $\mathrm{N}$ take the following values so that the total thickness of the AF is constant at $10 \mathrm{~nm}:(\mathrm{t} ; \mathrm{N})=(2.5 ; 2)$ and $(1 ; 5)$. After deposition, room-T EB is set by field cooling (FC) the samples in a furnace from $573 \mathrm{~K}$ for $90 \mathrm{~min}$ down to room-T. The magnetic field applied during cooling is positive in the sample plane and its amplitude of $10 \mathrm{kOe}$ saturates the $\mathrm{CoFeB}(2 \mathrm{~nm}) / \mathrm{NiFe}$ $(1.5 \mathrm{~nm}) \mathrm{F}$ layer. In addition, the $\mathrm{T}$ of $573 \mathrm{~K}$ is large enough so that, following this initial FC, all the AF entities with $\mathrm{T}_{\mathrm{B}}$ larger than room- $\mathrm{T}$ are oriented toward the positive direction. ${ }^{17}$ Hysteresis loops are then measured at room-T. Subsequent initial positive $\mathrm{FC}$ is continued down to $4 \mathrm{~K}$ in a vibrating sample magnetometer (VSM). $\mathrm{DT}_{\mathrm{B}}$ in the range of $4-473 \mathrm{~K}$ are then deduced from hysteresis loops measured at $4 \mathrm{~K}$ by VSM after a specific procedure which includes FC from incremental annealing temperatures $\left(\mathrm{T}_{\mathrm{a}}\right)$. The typical evolution of hysteresis loops after various $T_{a}$ is shown elsewhere. $^{17,20}$

Figure 1 shows the variations with $\mathrm{T}_{\mathrm{a}}$ of the normalized loop shifts, $\mathrm{H}_{\mathrm{E}} /\left|\mathrm{H}_{\mathrm{E}}\left(\mathrm{T}_{\mathrm{a}}=4 \mathrm{~K}\right) /\right|$ and the corresponding derivatives for our F/AF multilayers with various AFs. From the initial state where all the AF entities contributing to $\mathrm{EB}$ are oriented positively, the procedure consists in gradually reversing the $\mathrm{AF}$ entities by use of negative $\mathrm{FC}$ down to $4 \mathrm{~K}$ from incremental $\mathrm{T}_{\mathrm{a}}$. After each increment of $\mathrm{T}_{\mathrm{a}}$, a hysteresis loop is measured at $4 \mathrm{~K}$. Its shift in field, $\mathrm{H}_{\mathrm{E}}$, integrates $\mathrm{AF}$ entities with $T_{B}$ larger than $T_{a}$ (unaffected by the $F C$ at $T_{a}$ and still initially oriented positively) minus AF entities with $\mathrm{T}_{\mathrm{B}}$ lower than $\mathrm{T}_{\mathrm{a}}$ (reoriented negatively). A gradual change in the amplitude and sign of $\mathrm{H}_{\mathrm{E}}$ is observed in Fig. 1(a) since the higher the $T_{a}$, the more the reversed entities. In addition and by definition, the derivative $\delta \mathrm{H}_{\mathrm{E}} / \delta \mathrm{T}_{\mathrm{a}}$ vs $\mathrm{T}_{\mathrm{a}}$ in Fig. 1(b) corresponds to $\mathrm{DT}_{\mathrm{B}} \cdot{ }^{17}$ Thus: (i) an inflection point for $\mathrm{H}_{\mathrm{E}} \mathrm{vs}$ $\mathrm{T}_{\mathrm{a}}$ denotes a peak in the distribution and (ii) the amplitude $\Delta$ around the inflection is the surface, $\mathrm{S}$ of the corresponding peak (see Fig. 1). In the following, $\Delta$ is the difference between $\mathrm{H}_{\mathrm{E}}$ after $\mathrm{T}_{\mathrm{a}}=4$ and $200 \mathrm{~K}$ (i.e., after the low- $\mathrm{T}$ inflection). The two contributions to $\mathrm{DT}_{\mathrm{B}}$ can be observed in Fig. 1. The low-T contribution is known to originate from AF interfacial spin-glass-like phases. ${ }^{14-19}$ Given that, $\Delta$ [Fig. 1(a)] or S [Fig. 1(b)] measures the glassy character of the interface. In the following and to ease the interpretation, this glassy character is expressed in percentage: $\Delta^{*}$ equals $\Delta$ normalized to the total expected variations of $\mathrm{H}_{\mathrm{E}}$, i.e., 2 for normalized $H_{E}$. The second inflection point in the $H_{E}$ vs $T_{a}$ variations [Fig. 1(a)] corresponds to the high-T contribution to $\mathrm{DT}_{\mathrm{B}}$ [Fig. 1(b)] and is related to the grains stability and
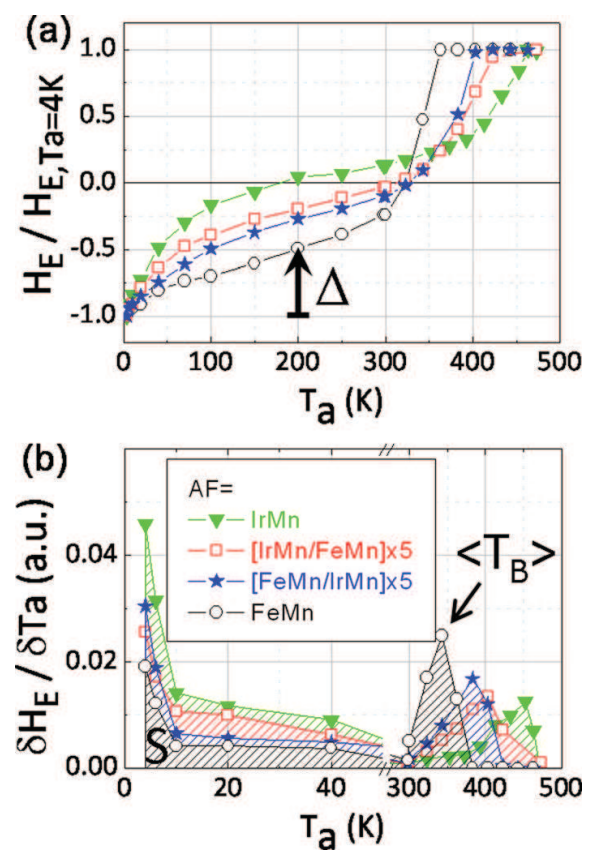

FIG. 1. (a) Typical variations with the annealing temperatures $\left(\mathrm{T}_{\mathrm{a}}\right)$ of the normalized loop shift $\left(\mathrm{H}_{\mathrm{E}} / \mathrm{H}_{\mathrm{E}}\left(\mathrm{T}_{\mathrm{a}}=4 \mathrm{~K}\right) \mathrm{l}\right)$ deduced from hysteresis loops measured at $4 \mathrm{~K}$ by VSM for $\mathrm{CoFeB}(2 \mathrm{~nm}) / \mathrm{NiFe}(1.5 \mathrm{~nm}) / \mathrm{AF}$, subject to a procedure detailed within the text and involving various $\mathrm{T}_{\mathrm{a}}$. The AF layers are: $\operatorname{IrMn}(10 \mathrm{~nm}),[\operatorname{IrMn}(1 \mathrm{~nm}) / \mathrm{FeMn}(1 \mathrm{~nm})]_{\mathrm{x} 5}$, [FeMn $(1 \mathrm{~nm}) / \mathrm{IrMn}$ $(1 \mathrm{~nm})]_{\mathrm{x} 5}$ and FeMn $(10 \mathrm{~nm})$. (b) Variations with $\mathrm{T}_{\mathrm{a}}$ of $\delta \mathrm{H}_{\mathrm{E}} / \delta \mathrm{T}_{\mathrm{a}}$ representing the blocking temperature distributions.

sizes dispersion. ${ }^{22-24}$ This contribution is centred on $\left\langle T_{B}\right\rangle$ [see Fig. 1(b)].

For the various AFs, Fig. 2(a) shows the amount of interfacial spin-glass, $\Delta^{*}$ deduced from Fig. 1(a). The F/AF magnetic interfacial quality varies from a glassy interface with $\operatorname{IrMn}(\sim 52 \%)$ to a twice less glassy interface with FeMn $(\sim 25 \%)$ via an intermediate value with $[\operatorname{IrMn}(\mathrm{t}) /$ $\operatorname{FeMn}(\mathrm{t})]_{\mathrm{xN}}$ repetitions $(\sim 38 \%)$. The differences between IrMn $\left(\mathrm{Ir}_{20} \mathrm{Mn}_{80}\right)$ and FeMn $\left(\mathrm{Fe}_{50} \mathrm{Mn}_{50}\right)$ were already observed and ascribed to the larger proportion of $\mathrm{Mn}$ atoms for the IrMn. ${ }^{17,18}$ It was inferred that the larger the amount of $\mathrm{Mn}$ atoms, the more glassy the interface. In particular, Mn atoms diffuse at the interface and create spin-glass phases. Lowering this via the addition of diffusion barriers was recently evidenced. ${ }^{25}$ The intermediate value obtained with $[\operatorname{IrMn}(\mathrm{t}) / \mathrm{FeMn}(\mathrm{t})]_{\mathrm{xN}}$ repetitions is independent on the repetitions parameters $(\mathrm{t} ; \mathrm{N})$. This implies that alloys likely form rather than well separated layers and well defined interfaces within the repetition. This is surely related to layers intermixing and alloying occurring during both deposition and post-deposition FC from $573 \mathrm{~K}$ (Refs. 26-30). Although the science of layers interdiffusion at the atomic scale involves many complex aspects out of the scope of the present article, one of the major empirical conclusions here is that simply stacking (alloying) IrMn and FeMn offers a knob to tune the magnetic interface quality exactly between that of pure IrMn and FeMn.

Figure 2(b) shows the hysteresis loop shift amplitude, $\mathrm{H}_{\mathrm{E}}$ measured at $\mathrm{T}_{\mathrm{m}}=4$ and $300 \mathrm{~K}$ for the various AFs. For a given $T_{m}, H_{E}$ is related to many parameters such as the 
(a)

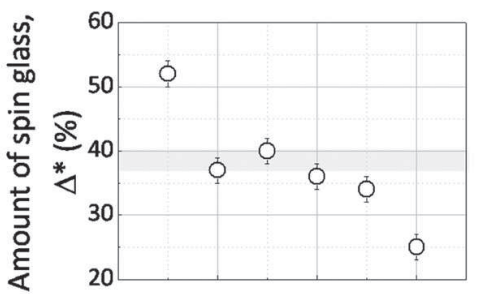

(b)

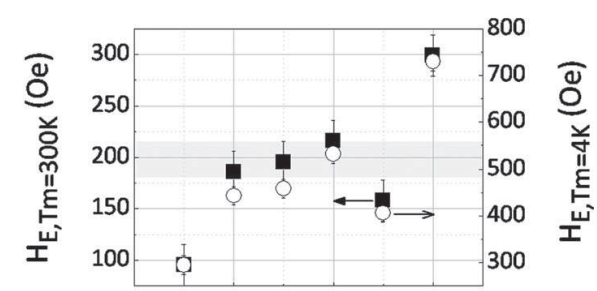

(c)

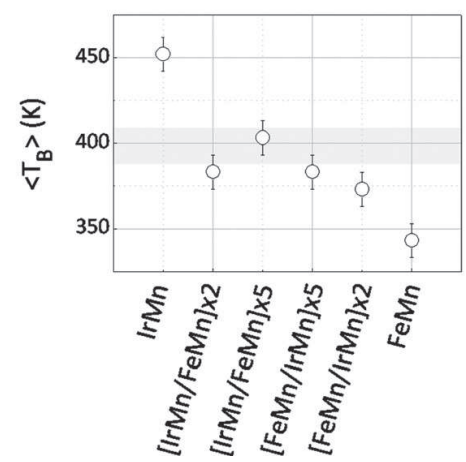

FIG. 2. For $\mathrm{CoFeB}(2 \mathrm{~nm}) / \mathrm{NiFe}(1.5 \mathrm{~nm}) / \mathrm{AF}$, with $\mathrm{AF}=\operatorname{IrMn}(10 \mathrm{~nm})$, $[\operatorname{IrMn}(\mathrm{t} n m) / \mathrm{FeMn}(\mathrm{t} \mathrm{nm})]_{\mathrm{xN}},[\mathrm{FeMn}(\mathrm{t} \mathrm{nm}) / \mathrm{IrMn}(\mathrm{t} \mathrm{nm})]_{\mathrm{xN}}$ and FeMn $(10 \mathrm{~nm}),(\mathrm{t} ; \mathrm{N})=(2.5 ; 2)$ and $(1 ; 5)$ : (a) amount of spin-glass, $\Delta^{*}=\Delta / 2$, see Fig. 1(a); (b) hysteresis loop shift, $\mathrm{H}_{\mathrm{E}}$ measured at $\mathrm{T}_{\mathrm{m}}=4$ and $300 \mathrm{~K}$ and (c) mean blocking temperature, of the high-T contribution, see Fig. 1(b). For every plot, the grey area is, within error bars, the mean value calculated from the IrMn and FeMn experimental data.

magnetic anisotropies of the $\mathrm{F}$ and $\mathrm{AF}\left(\mathrm{K}_{\mathrm{F}}, \mathrm{K}_{\mathrm{AF}}\right)$, the $\mathrm{F}-\mathrm{AF}$ interfacial exchange stiffness $\left(\mathrm{J}_{\mathrm{F}-\mathrm{AF}}\right)$, the $\mathrm{F}$ and $\mathrm{AF}$ magnetic moments $\left(\mathrm{m}_{\mathrm{F}}, \mathrm{m}_{\mathrm{AF}}\right)$, and the amount of $\mathrm{AF}$ entities that remain pinned when cycling the $\mathrm{F}^{2,17}$ Although this latter parameter itself results as well from a complex compromise between $\mathrm{J}_{\mathrm{F}-\mathrm{AF}}$, AF-AF exchange stiffness $\left(\mathrm{J}_{\mathrm{AF}-\mathrm{AF}}\right)$, grains volumes, amount of spin-glasses on top of each grain, etc., the $\mathrm{DT}_{\mathrm{B}}$ plotted in Fig. 1(b) directly measures the relative amount of AF entities remaining pinned at $T=T_{a}$. Essentially, $\mathrm{H}_{\mathrm{E}}$ measured at $\mathrm{T}_{\mathrm{m}}$ is proportional to a complex function that depends on $\mathrm{T}_{\mathrm{m}}$ and includes the above cited parameters: $g\left(T_{m}\right)$, times the integrand of the $D T_{B}$ from the initial FC-T (here $573 \mathrm{~K}$ ) to $\mathrm{T}_{\mathrm{m}} \cdot{ }^{17}$ The increase of $\mathrm{H}_{\mathrm{E}}$ between 4 and $300 \mathrm{~K}$ observed in Fig. 2(b) for all samples is ascribed both to the thermal variations of the intrinsic physical parameters and to the fact that more $\mathrm{AF}$ entities are frozen at $4 \mathrm{~K}$ than at $300 \mathrm{~K}$ [see Fig. 1(b)]. Figure 2(b) also shows that the $[\operatorname{IrMn}(\mathrm{t}) / \mathrm{FeMn}(\mathrm{t})]_{\mathrm{xN}}$ alloys all have similar values intermediate between those of $\mathrm{IrMn}$ and FeMn: $\mathrm{H}_{\mathrm{E}, \mathrm{FeMn}}>$ $\mathrm{H}_{\mathrm{E},[\mathrm{IrMn} / \mathrm{FeMn}]}>\mathrm{H}_{\mathrm{E}, \mathrm{IrMn}}$. This is partly due to $\mathrm{J}_{\mathrm{F}-\mathrm{AF}}$ : FeMn coupled to NiFe shows larger $\mathrm{J}_{\mathrm{F}-\mathrm{AF}}$ than IrMn. Additionally, it looks consistent that $\mathrm{J}_{\mathrm{NiFe}-[\mathrm{IrMn} / \mathrm{FeMn}]}$ stands between $\mathrm{J}_{\mathrm{NiFe}-\mathrm{FeMn}}$ and $\mathrm{J}_{\mathrm{NiFe}-\mathrm{IrMn}}$ since as measured and discussed above, the $[\operatorname{IrMn}(\mathrm{t}) / \mathrm{FeMn}(\mathrm{t})]_{\mathrm{xN}}$ magnetic interface quality is intermediate between FeMn and IrMn,. The differences between $\mathrm{H}_{\mathrm{E}, \mathrm{FeMn}}$, $\mathrm{H}_{\mathrm{E},[\mathrm{IrMn} / \mathrm{FeMn}]}$ and $\mathrm{H}_{\mathrm{E}, \mathrm{IrMn}}$ are also in part related to the amount of stable AF entities which is larger for FeMn compared to $[\operatorname{IrMn}(\mathrm{t}) / \mathrm{FeMn}(\mathrm{t})]_{\mathrm{xN}}$ and $\operatorname{IrMn}$.

Figure 2(c) represents the mean $\mathrm{T}_{\mathrm{B}}$ of the high- $\mathrm{T}$ contribution, extracted from Fig. 1(b). The $[\operatorname{IrMn}(\mathrm{t}) / \mathrm{FeMn}(\mathrm{t})]_{\mathrm{xN}}$ repetitions all show similar values of $\left\langle\mathrm{T}_{\mathrm{B}}\right\rangle$ which confirms the likely formation of alloys rather than distinct layers separated by defined interfaces. Contrary to Fig. 1(a) where only the magnetic interfacial quality is probed, $\left\langle\mathrm{T}_{\mathrm{B}}\right\rangle$ is associated with the AF grains stability over $\mathrm{F}$ magnetization reversal, and is related to both the coupling of the AF to the $\mathrm{F}\left(\mathrm{J}_{\mathrm{F}-\mathrm{AF}}\right)$ and the intrinsic thermal stability of the $\mathrm{AF}$ grains $\left(\mathrm{K}_{\mathrm{AF}} \cdot \mathrm{V}_{\mathrm{AF}}\right) \cdot{ }^{17,22-24}$ It seems that alloying IrMn and FeMn also results in $\mathrm{AF}$ grains stabilities intermediate between IrMn and FeMn.

To conclude, the F/AF storage layer building block of spintronics devices was studied. Alloying IrMn and FeMn offered an additional knob, easy to implement, to adjust at the same time the interfacial glassy character, $\mathrm{H}_{\mathrm{E}}$ and $\mathrm{AF}$ grains stability to values intermediate between those of IrMn and FeMn. This responds to an industrial need and in particular provides an ideal material for a TA-MRAM storage layer with better stability than FeMn at rest-T but requiring less write power consumption than IrMn and with improved magnetic interfacial quality compared to IrMn.

${ }^{1}$ I. L. Prejbeanu et al., J. Phys. D: Appl. Phys. 46, 074002 (2013).

${ }^{2}$ J. Nogués and I. K. Schuller, J. Magn. Magn. Mater. 192, 203 (1999); A.

E. Berkowitz and K. Takano, ibid. 200, 552 (1999).

${ }^{3}$ L. Lombard et al., J. Appl. Phys. 107, 09D728 (2010).

${ }^{4}$ C. Papusoi et al., J. Appl. Phys. 104, 013915 (2008).

${ }^{5}$ J. P. Nozières et al., J. Appl. Phys. 87, 3920 (2000).

${ }^{6}$ M. J. Carey et al., Appl. Phys. Lett. 81, 5198 (2002).

${ }^{7}$ T. Ohtsu et al., IEEE Trans. Magn. 43, 2211 (2007).

${ }^{8}$ B. Dai et al., Appl. Phys. Lett. 85, 5281 (2004).

${ }^{9}$ G. W. Anderson and Y. M. Huai, J. Appl. Phys. 87, 4924 (2000).

${ }^{10}$ S.-S. Lee et al., J. Appl. Phys. 95, 7525 (2004).

${ }^{11}$ T. Yamaoka et al., J. Phys. Soc. Japan 31, 301 (1971).

${ }^{12}$ Y. Endoh and Y. Ishikawa, J. Phys. Soc. Japan 30, 1614 (1971).

${ }^{13}$ P. F. Ladwig et al., J. Appl. Phys. 94, 979 (2003).

${ }^{14}$ K. Takano et al., Phys. Rev. Lett. 79, 1130 (1997).

${ }^{15}$ J. Ventura et al., J. Appl. Phys. 101, 113901 (2007).

${ }^{16} \mathrm{M}$. Ali et al., Nature Mater. 6, 70 (2007).

${ }^{17}$ V. Baltz et al., Phys. Rev. B 81, 052404 (2010).

${ }^{18}$ V. Baltz, Appl. Phys. Lett. 102, 062410 (2013).

${ }^{19}$ V. Baltz et al., Appl. Phys. Lett. 96, 262505 (2010).

${ }^{20}$ S. Soeya et al., J. Appl. Phys. 76, 5356 (1994).

${ }^{21}$ J. Wu et al., Phys. Rev. Lett. 104, 217204 (2010).

${ }^{22}$ E. Fulcomer and S. H. Charap, J. Appl. Phys. 43, 4190 (1972).

${ }^{23}$ V. Baltz et al., Phys. Rev. B 72, 104419 (2005).

${ }^{24}$ K. O'Grady et al., J. Magn. Magn. Mater. 322, 883 (2010).

${ }^{25}$ K. Akmaldinov et al., Appl. Phys. Lett. 103, 042415 (2013).

${ }^{26}$ R. M. Bozorth, Ferromagnetism (D. Van Nostrand Company Inc., 1951).

${ }^{27}$ X. W. Zhou et al., Acta Mater. 49, 4005 (2001).

${ }^{28}$ L. Lechevallier et al., J. Appl. Phys. 112, 043904 (2012).

${ }^{29}$ F. Letellier et al., J. Phys. D: Appl. Phys. 45, 275001 (2012).

${ }^{30}$ M.-A. Nicolet, Thin Solid Films 52, 415 (1978). 